Intervenção em Saúde do Trabalhador

\author{
Maria Cristina Strausz ${ }^{\mathrm{a}}$ \\ (iD) http://orcid.org/0000-0002-7835-9238 \\ Maria Cristina Rodrigues Guilam ${ }^{\mathrm{a}}$ \\ (iD) https://orcid.org/0000-0003-4242-3530 \\ Simone Santos Oliveira ${ }^{\mathrm{a}}$ \\ (iD) https://orcid.org/0000-0001-5477-6216
}

a Fundação Oswaldo Cruz (Fiocruz). Rio de Janeiro, RJ, Brasil.

Contato:

Maria Cristina Strausz

E-mail:

strausz@ensp.fiocruz.br

Trabalho baseado na tese de doutorado de Maria Cristina Strausz, intitulada "Produção do conhecimento em Saúde Coletiva: um olhar a partir da saúde do trabalhador", defendida na Escola Nacional de Saúde Pública Sérgio Arouca, Fundação Oswaldo Cruz, Rio de Janeiro, 2014.

Os autores declaram que o estudo não foi subvencionado e que não há conflitos de interesses.

Os autores informam que o trabalho não foi apresentado em eventos científicos.

\section{A intervenção em saúde do trabalhador na perspectiva dos atores históricos do campo}

\author{
Worker's health intervention: the historical actors' perspective
}

\section{Resumo}

Introdução: o campo da Saúde do Trabalhador (ST) se assenta em uma concepção que pressupõe uma visão ambiental, social e histórica do processo saúde-doença, ultrapassando os limites dos locais de trabalho. Objetivo: apresentar diferentes facetas da intervenção em ST a partir de um resgaste histórico da construção do campo, destacando visões de seus instituidores. Métodos: entrevistas com agentes históricos do campo considerados informantes-chave. Para análise do conteúdo abordado nas entrevistas foram eleitas as categorias: os alicerces da intervenção e sua viabilidade na estruturação dos serviços; intervenção como produção de conhecimento e normativa; a propagação da intervenção: formação e informação. Resultados: na perspectiva desses atores, a intervenção é uma marca do campo que se apresenta na produção científica e técnica, bem como nos serviços; fortemente aliada ao movimento dos trabalhadores enquanto sujeitos, tanto nas ações como na produção compartilhada de conhecimento. Conclusão: no campo da ST, a intervenção tem como expressão máxima a Vigilância em Saúde do Trabalhador. Também se manifesta nas modalidades de pesquisa-ação, pesquisa-intervenção e comunidade ampliada de pesquisa, que afirmam o protagonismo dos trabalhadores e a valorização da subjetividade para os processos de transformação.

Palavras-chave: saúde do trabalhador; intervenção; pesquisa-ação.

\begin{abstract}
Introduction: the Worker's Health (WH) field is based on a conception that presupposes an environmental, social and historical view of health-disease process beyond the workplace limits. Objective: to present different facets of the WH intervention from a historical recovery of the field construction, highlighting its founders' views. Methods: interviews with historical field actors considered key informants. For the interviews content analysis, the following categories were defined: the intervention foundation and its feasibility for services structuring; intervention as knowledge production and regulation; the intervention spreading: training and information. Results: from these actors' perspective, intervention is intrinsic to the field, and is present in scientific and technical production, as well as in services; strongly allied to the workers' movement as subjects, both in actions and in the shared production of knowledge. Conclusion: in the WH field, intervention has the Workers' Health Surveillance as its maximum expression. It is also shown in form of action-research, intervention-research and broader research community, which affirms workers' protagonism and the subjectivity growing importance for the transformation processes.
\end{abstract}

Keywords: occupational health; intervention; action-research. 


\section{Introdução}

A Saúde do Trabalhador (ST) surgiu como área de saberes e práticas no âmbito da Saúde Coletiva a partir do questionamento do modelo biomédico pela medicina social latino-americana, da sua aproximação com as Ciências Sociais e com o Movimento Operário Italiano (MOI) dos anos 1960. No Brasil, a incorporação das Ciências Sociais foi o salto qualitativo que permitiu apreender a complexidade das questões relativas à saúde dos trabalhadores $^{1}$. O conceito marxista de processo de trabalho é apropriado como categoria explicativa central do desgaste dos trabalhadores, o que inclui a subjetividade dos atores envolvidos ${ }^{2}$. Este conceito configura o marco definidor do que se denomina campo da ST na concepção de seus autores ${ }^{3-5}$. Trata-se de uma concepção que pressupõe uma visão ambiental, social e histórica do processo saúde-doença, ultrapassando os limites dos locais de trabalho. Como tal, foi contemplado no documento-base da I Conferência Nacional de Saúde do Trabalhador em 1986, a partir da contribuição dos primeiros formuladores do campo ${ }^{6}$.

Esse campo apresentou-se como contraponto à saúde ocupacional, aliando o reconhecimento do saber operário e a categoria processo de trabalho como diferencial para os estudos da área. Dessa forma, a ST prioriza a análise e a intervenção no trabalho e sua relação com o processo saúde-doença. Essa perspectiva busca romper com as concepções hegemônicas, uni ou multicausal, que desconsideram a dimensão social e histórica do trabalho e da saúde/doença ${ }^{7,8}$.

A ST emerge dos movimentos político e social, inserindo-se na rede pública de saúde apoiada pela produção acadêmica. Neste sentido, o seu campo pressupõe um corpo de práticas e teorias interdisciplinares, multiprofissionais e interinstitucionais no interior da saúde coletiva ${ }^{9}$.

O campo foi demarcado por uma construção teórica marxista e gramsciana recuperada pelo MOI nos anos 1960 a partir de Ivar Oddone ${ }^{10}$ e de Enrico Berlinguer $^{11}$ e adaptada para a América Latina baseada em formulações de Asa Cristina Laurell e Mariano Noriega ${ }^{7}$, no México, e Cristina Possas ${ }^{12}$ e Anamaria Tambellini ${ }^{6}$, no Brasil, nas décadas de 1970 e 1980.

Machado ${ }^{13}$ refere-se à incorporação de metodologias do MOI, como o mapeamento de riscos, tanto na legislação em vigor como entre as utilizadas nas ações de vigilância em saúde do trabalhador. Além do mapeamento de riscos, outras metodologias que foram desenvolvidas sob a influência de Oddone, como a Comunidade Científica Ampliada (CCA), têm sido adaptadas, aperfeiçoadas e atualizadas no Brasil e na França sob o nome de Comunidade Ampliada de Pesquisa (CAP) e Instrução ao Sósia ${ }^{14}$.

O MOI inovou ao mudar a lógica de produção de saber, trazendo a experiência coletiva dos trabalhadores como principal fonte de conhecimento ${ }^{7,15}$. Sua premissa é a valorização da experiência e do conhecimento do trabalhador na luta por melhores condições de trabalho e suas diretrizes são a não-monetarização do risco, a não-delegação (exprimindo a recusa de delegar aos especialistas o julgamento sobre a nocividade das condições de trabalho e a fixação dos seus padrões) e a validação consensual ou o julgamento coletivo da experiência dos operários relativa às condições de trabalho a partir dos grupos homogêneos de risco, isto é, aqueles trabalhadores que vivem uma experiência submetidos à mesma nocividade ambiental. Este movimento buscou compreender-transformar as situações de trabalho a partir da confrontação entre os saberes formais dos técnicos, os conceitos científicos dos pesquisadores e os saberes informais dos trabalhadores (conceitos espontâneos). Para Oddone ${ }^{11}$, os técnicos não devem funcionar como experts que indicam os caminhos tecnicamente corretos, mas assessorar os trabalhadores para que, com seus conhecimentos, adquiridos no chão de fábrica, possam ultrapassar alguns dos problemas que enfrentam.

Por isso, a geração do Modelo Operário (MO) de conhecimento a partir do MOI se define como uma inovação que constituiu um arcabouço conceitual e metodológico distinto, justamente pela valorização da prática, da ação, do trabalho concreto, realizados por equipe interdisciplinar, com a participação dos trabalhadores como protagonistas do processo ${ }^{16}$.

Para Souza e Mendonça ${ }^{16}$, em análise sobre a obra de Oddone,

[...] MO pode ser interpretado como um plano de conhecimento e de ação política de luta pela saúde, concebido sob o interesse da classe trabalhadora. Seu escopo teórico-metodológico, princípios e pressupostos representam um modo de produção compartilhada de conhecimento sobre a relação saúde e trabalho, sendo construído pela comunidade de trabalhadores em cooperação com pesquisadores a partir da década de sessenta. Ademais, ele é importante referência e fonte de inspiração até os dias atuais. (p. 3)

A ST assume a mesma lógica enquanto campo de produção compartilhada de conhecimento, tendo esta como um valor, e trouxe como novidade, em oposição aos conceitos clássicos da Medicina do Trabalho e da Saúde Ocupacional, a incorporação de algumas variáveis que moldaram uma nova categoria de análise. Destacam-se entre estas: 
[...] a ampliação do objeto de intervenção sobre a produção (processos e ambientes de trabalho), incorporando outras variáveis sociais, econômicas etc.; a sujeição dos determinantes à capacidade de intervenção da saúde pública; a incorporação do trabalhador, enquanto sujeito e protagonista, ao desenvolvimento do campo de produção de conhecimentos e de intervenção; e, entre outras diferenças conceituais, a superação do limite contratual do trabalho como enfoque normativo de garantia da saúde no exercício cotidiano de trabalhar"17 (p. 145-6).

A Lei Orgânica da Saúde acrescenta a relação trabalho-saúde ao objeto da saúde com destaque à questão da vigilância, no sentido de resgatar para o setor a capacidade de intervir nos processos determinantes dos agravos decorrentes desta relação ${ }^{15}$.

A Política Nacional de Saúde do Trabalhador e da Trabalhadora (PNSTT), de 2012, enfatiza a Vigilância em Saúde do Trabalhador (Visat) em todos os seus aspectos, inclusive na inserção do controle social como instrumento de vigilância, de ação e de intervenção, por parte dos segmentos organizados da sociedade sobre as ações do Estado ${ }^{18}$.

A mesma política estabelece o entendimento de que a intervenção, no âmbito da Visat, é o deflagrador de um processo contínuo, ao longo do tempo, em que a pesquisa é sua parte indissolúvel, subsidiando e aprimorando a própria intervenção ${ }^{19}$.

Este artigo tem como objetivo apresentar diferentes facetas da intervenção em ST, a partir de um resgaste histórico da construção do campo, destacando visões de seus instituidores.

\section{Percurso metodológico}

A análise da configuração da área temática ST foi realizada a partir de entrevistas com agentes históricos do campo considerados informantes-chave ${ }^{20}$.

O critério de seleção dos entrevistados obedeceu ao método bola de neve (snow-ball): cada entrevistado indicou novos informantes dotados de capital simbólico ${ }^{21}$. Muitos foram agentes históricos instituidores do campo; alguns se destacam por sua produção bibliográfica e acadêmica, outros por sua inserção junto aos movimentos sociais ou aos serviços. Ressalta-se que adicionalmente foi levado em conta, para a seleção dos entrevistados, a origem de atuação geográfica e institucional, a fim de que não houvesse uma concentração de entrevistados da região Sudeste. Não foram indicados agentes históricos do campo nas regiões Norte e Centro-Oeste. Apenas uma pessoa da região Sul foi indicada, mas não houve a saturação necessária do número de indicações nem a possibilidade de realização da entrevista, por questões de logística.

Um total de dez entrevistados assinaram Termo De Compromisso Livre e Esclarecido, concordando com os termos da pesquisa, bem como com a sua identificação. Além disso, obtiveram uma cópia gravada e/ou transcrita delas, de acordo com o parecer do Comitê de Ética em Pesquisa da Escola Nacional de Saúde Pública (CEP-ENSP) n $\mathrm{n}^{\circ}$ 53.129, CAA: 04580512.8.0000.5240. Foram entrevistados: Anamaria Testa Tambellini, Carlos Minayo-Gomez, Elizabeth Costa Dias, Francisco Antônio de Castro Lacaz, Herval Pina Ribeiro, Jorge Mesquita Huet Machado, Letícia Costa Coelho Nobre, Lia Giraldo da Silva Augusto, Luíz Augusto Cassanha Galvão e Vilma de Souza Santana. Observa-se que, para a identificação dos entrevistados, utilizou-se nome e sobrenome, de forma reduzida; quando foi usada a referência bibliográfica dos próprios entrevistados, foram adotadas as regras de citação acadêmica; e para citação das falas das entrevistas, foram usadas suas iniciais.

Das entrevistas, foram selecionadas falas e posicionamentos referentes às diversas formas de intervenção em ST, categorizadas como: Os alicerces da intervenção e sua viabilidade na estruturação dos serviços; Intervenção como produção de conhecimento e normativa; e A propagação da intervenção: formação e informação.

\section{Resultados e Discussão}

\section{Os alicerces da intervenção e sua viabilidade na es- truturação dos serviços}

Esta categoria procura retomar as origens do campo, identificando na sua formação as bases e princípios estruturantes.

A ST tem origem na efervescência do Movimento da Reforma Sanitária Brasileira, que culminou com a redemocratização do país. Inicialmente se configurou como um movimento de luta dos trabalhadores pela saúde, que resultou na criação do Departamento Intersindical de Estudos e Pesquisas de Saúde e dos Ambientes de Trabalho (Diesat) e de programas de saúde do trabalhador. Após sua garantia constitucional, foi dado início a um processo de institucionalização ao longo dos anos 1990 e 2000, a partir do estabelecimento de um arcabouço legal e a formação da Rede Nacional de Atenção Integral à Saúde do Trabalhador (Renast).

Jorge Machado, primeiro coordenador do Programa de Saúde do Trabalhador (PST) do estado do Rio de Janeiro e mais tarde coordenador geral de saúde do trabalhador do Ministério da Saúde, considera o trabalho como uma ação, um componente 
estruturante do processo civilizatório do mundo e da construção dos modos de viver. Alega que, apesar da sua importância como determinante da saúde, seu aprofundamento é negligenciado, à medida que permanece periférico dentro do sistema de saúde.

Anamaria Tambellini, fundadora do Centro de Estudo de Saúde do Trabalhador e Ecologia Humana (Cesteh) em 1985, ao se referir ao princípio da intersetorialidade, alega que ST foi a primeira área dentro da esfera da saúde que articulou setores dentro do aparelho de estado para pensar uma política integrada:

A saúde do trabalhador, tanto aqui como no México, com a Asa Cristina, apareceu a partir da preocupação com a determinação social da doença. A Asa Cristina trabalhou muito na área acadêmica e nós aqui construímos uma área da saúde do trabalhador para o SUS, dentro do sistema do SUS. (A.T.T.)

Letícia Nobre, coordenadora do Centro de Referência de Saúde do Trabalhador da Bahia (Cerest-BA), corrobora com Anamaria Tambellini e acrescenta o princípio de interdisciplinaridade, afirmando que a ST é um recorte da Saúde Coletiva que articula outras áreas do conhecimento numa dimensão que vai à raiz da determinação social com os aportes da sociologia, da economia, da política, das várias áreas do direito, das engenharias, das ciências biológicas e da medicina.

Luiz Galvão, coordenador do Cesteh de 1989 a 1991, depois Diretor do Programa Especial sobre Desenvolvimento Sustentável e Equidade em Saúde da Organização Panamericana da Saúde, afirma que o centro tem uma grande relevância porque é um instituto de pesquisa pioneiro dentro de um sistema de saúde no Brasil, como o National Institute for Occupational Safety and Health (Niosh), nos Estados Unidos, que é parte do Centers for Disease Control and Prevention (CDC), e o Institute of Environmental Medicine (IMM) do Karolinska Institutet, na Suécia.

Carlos Minayo-Gomez refere que no início dos anos 1990 introduziu no Cesteh a perspectiva das Ciências Sociais, a partir de demanda do Sindicato dos Químicos do Rio de Janeiro sobre uma grande indústria de cloro-soda. Foi construído um projeto que integrava todas as áreas do centro, numa perspectiva interdisciplinar: ambulatório com avaliação neurológica e neuropsicológica, laboratório de toxicologia, entrevistas com os trabalhadores e trabalhadoras (abordagem de gênero). Aliados ao centro estavam o Conselho Estadual de Saúde do Trabalhador, com seu comitê técnico da indústria química atuando na intervenção e na Visat e o poder legislativo representado pela Comissão de Ciência e Tecnologia (C\&T) da Assembleia Legislativa do Estado do Rio de Janeiro (Alerj). Na visão do entrevistado, esta deveria ser a forma de atuação ideal da ST.
A implantação de serviços de saúde do trabalhador na rede de saúde se deu a partir da demanda do movimento sindical, como relata Lia Giraldo, que criou o primeiro Centro de Saúde do Trabalhador (Cesat) em 1983, quando tornou-se diretora regional de saúde na Baixada Santista. Ela descreve ainda que a Visat já funcionava aplicando o princípio da intersetorialidade a partir do acionamento de diversas áreas, como a fiscalização do trabalho e as vigilâncias sanitária e epidemiológica. Faziam o diagnóstico do nexo causal a partir do chão da fábrica, não assistindo apenas ao evento sentinela, mas também os demais trabalhadores que estavam sendo avaliados no processo produtivo, usando a metodologia de inspiração italiana de grupo homogêneo de risco. Conquistaram também a delegação da Previdência Social, e passaram a preencher o Laudo de Exame Médico (LEM) da Comunicação de Acidente de Trabalho (CAT) no próprio serviço.

Além do relatado anterior, Lia Giraldo também foi protagonista no desvelamento da epidemia de benzenismo, em 1983, realizando mais de dois mil diagnósticos. Para tanto, buscou uma nova formação em hematologia, a fim de obter o reconhecimento da exposição dos trabalhadores como questão de Saúde Pública não só para fins de tratamento, como de reconhecimento previdenciário. Nesse processo nasceu o PST da Baixada Santista, que foi base de treinamento para os profissionais da Bahia e do Rio de Janeiro. Logo após, em 1986, deram início os programas do Rio de Janeiro, da Bahia, de Santa Catarina e de Minas Gerais.

Francisco Lacaz relata que foi diretor de uma unidade de saúde nos anos 1970, depois coordenou o Instituto de Saúde, que não era uma estrutura formal, mas que teve um papel importante, de nucleação de pesquisas. Esta instância do governo de São Paulo se propunha a ser o órgão de pesquisa da secretaria de saúde. Desta forma, ao mesmo tempo em que desenvolvia práticas na rede, como na criação de PST, também era um espaço de investigação. Em São Paulo houve a expansão do modelo de PST para outras regionais de saúde do estado, como o PST Rural, com a questão dos agrotóxicos no Vale da Ribeira, e uma vertente de investigação sobre o mercúrio e ainda das lesões por esforço repetitivo, por conta da demanda dos bancários no ABC Paulista.

Como em São Paulo, Nobre ${ }^{22}$ relata que na Bahia a ST teve origem nas raízes dos movimentos sociais e sindicais da década de 1980, juntamente com os movimentos da Reforma Sanitária e da redemocratização do país. Chama a atenção para o protagonismo da Central Única dos Trabalhadores (CUT) por meio de seu Coletivo de Saúde na realização da I Conferência Estadual de Saúde do Trabalhador da Bahia em 1987 e na criação do Centro de Estudos de Saúde do Trabalhador Salvador Allende (CESAT), hoje Centro de Referência em Saúde do Trabalhador (Cerest). 
Elizabeth Dias enfatiza a importância da organização de um serviço no âmbito da universidade (Universidade Federal de Minas Gerais - UFMG) para desvelamento do adoecimento relacionado ao trabalho, como campo de formação médica, de modo que isso pudesse entrar nas agendas políticas e nas agendas técnicas dos serviços de saúde. Para isso foi criado no âmbito da UFMG um ambulatório em parceria com a Fundação Jorge Duprat Figueiredo de Segurança e Medicina do Trabalho (Fundacentro), que dava o apoio na fiscalização do trabalho. Informa que diversos PST seguiram o mesmo caminho.

Corroborando com Elizabeth Dias sobre a importância da formação para o diagnóstico dos agravos relacionados ao trabalho, é emblemático o desvelamento da asbestose no Rio de Janeiro, quando uma profissional médica do Sistema Único de Saúde (SUS) identificou um caso após concluir sua formação como especialista em ST. Este caso índice teve o diagnóstico confirmado pelo Cesteh e revelou um contingente de trabalhadores expostos na indústria têxtil de amianto $^{(23)}$. Apoiado pela academia, foi formado o embrião da Associação Brasileira dos Expostos ao Amianto do Rio de Janeiro (Abrea-RJ), um movimento pelo banimento do amianto, que cresceu em diversos estados e que logrou êxito, após longa luta, em 2017, com a sentença favorável do Superior Tribunal Federal (STF) em 29 de novembro de 2017. Este caso ilustra perfeitamente a articulação entre a formação profissional em saúde com a Visat e o movimento social em defesa da saúde.

Também no Rio de Janeiro, o PST teve uma atuação diferenciada em relação aos de São Paulo e Bahia, uma vez que privilegiou a intervenção nos ambientes de trabalho, em vez da organização da assistência, entendendo que esta se daria em uma rede de serviços-sentinela ligada às universidades e centros de pesquisa, além da rede própria do SUS. Como estratégia, organizou uma instância não formal de participação dos trabalhadores a partir de suas representações sindicais, no final dos anos 1980, o Conselho Estadual de Saúde do Trabalhador (Consest). Ali eram decididas as prioridades para a intervenção nos locais de trabalho e organizadas as ações de Visat com atuação sindical. A composição do Consest era de técnicos em ST e de sindicatos e centrais sindicais. A partir da década de 1990 são formados os PST da capital e do município de Duque de Caxias, entre outros ${ }^{20}$.

Sobre os limites da intervenção enquanto ações de vigilância e assistência, Minayo-Gomez afirma que, apesar de a área possuir um arcabouço teórico-metodológico bem definido, ela ainda é atravessada por um conjunto de práticas diferenciadas, muitas vezes privilegiando somente a assistência ou uma ação pontual de fiscalização, que traz pouco impacto nas condições de trabalho. Isto se reflete também na produção de conhecimento. Afirma ainda que "alguns eventos temáticos segmentados por setores produtivos considerados prioritários para vigilância, ou que tratam da socialização de experiências, têm se mostrado altamente proveitosos" (p.23) para a qualificação das ações de Visat ${ }^{24}$.

\section{Intervenção como produção de conhecimento, elabo- ração de normas e políticas}

Lia Giraldo afirma que é um axioma do campo que a produção científica seja pautada pelos serviços e pelo movimento dos trabalhadores. Há uma distinção da Saúde Ocupacional e da Medicina do Trabalho, pois possui um marco epistêmico ligado a uma práxis.

[...] é um campo interdisciplinar e transdisciplinar suportado pelas disciplinas que você mobiliza e faz dialogar, [...] a gente poderia dizer que é um campo onde a gente pode praticar a ecologia dos saberes dentro dessa visão do Boaventura [Souza Santos]. É um campo de diálogo de saberes, [...] ele usa os métodos das várias disciplinas, ele se apoia numa episteme mais das ciências sociais [...]. (L.G.S.A.)

Para Anamaria Tambellini, a ideia de um novo campo de saber necessitava diferenciar-se a partir de novas metodologias que incorporassem outros saberes. Ela relata parte dessa jornada quando foi buscar no Instituto Alberto Luiz Coimbra de Pós-Graduação e Pesquisa de Engenharia da Universidade Federal do Rio de Janeiro (COPPE/UFRJ) novos atores para estudar o processo de trabalho no Brasil. Esta parceria trouxe para o Cesteh pesquisadores com a contribuição da Engenharia de Produção e da Ergonomia francofônica. Informa que partiu de uma grande preocupação teórico-metodológica de compatibilizar novos métodos com a natureza do objeto e a questão a ser trabalhada.

\begin{abstract}
A nossa preocupação maior era trabalhar as dimensões do processo de produção para conseguir ver como se concretizavam as relações sociais e técnicas do processo de produção no processo de trabalho. [...] A gente inclusive fazia estudos de caso, porque ninguém sabia como era uma fábrica, como aquilo funcionava, como aquilo era administrado, como se colocava as chamadas relações sociais que refletiam a relação capital $x$ trabalho. (A.T.T)
\end{abstract}

Este relato demonstra também que o setor Saúde Pública tinha pouco ou nenhum acesso ao processo produtivo, uma vez que até então este não era seu objeto. Nesse sentido, precisou ser desvelado a partir de novos aportes teórico-metodológicos para a compreensão dos processos de trabalho que dessem subsídios para a intervenção nos ambientes de trabalho. 
Havia adicionalmente uma grande preocupação em desvelar as representações sociais do processo saúde-trabalho, como forma de entender os riscos do adoecimento e da ocorrência de acidentes, uma vez que os sanitaristas possuíam a capacidade de identificar os perigos à saúde e os engenheiros de produção para identificar o processo de trabalho propriamente dito (as suas relações técnicas).

[...] e a gente trabalhava junto para separar o que era realmente relação técnica, [...] e quais eram as relações sociais que faziam com que o trabalho se organizasse de uma determinada maneira, que era capaz de maximizar ou minimizar riscos. (A.T.T)

Lia Giraldo concorda que, quanto aos métodos e técnicas, estes tiveram que ser adaptados à complexidade do objeto:

\begin{abstract}
É uma pesquisa mesmo mais engajada, uma pesquisa mais social, mais praxiológica e que está dirigida para os serviços, para o SUS. [...] A gente foi desenvolvendo e adaptando várias abordagens dos métodos qualitativos, trabalhar com as percepções e com a subjetividade [...] porque debaixo dessa tecnologia genérica de abordagem ecossistêmica, a gente tem ensaiado abordagens integrativas e participativas, sempre mais no campo da pesquisa-ação, [...] faz parte do nosso perfil de pesquisa que os nossos pesquisados, quando se trata de populações, participem tanto do processo de construção e de validação. (L.G.S.A.)
\end{abstract}

Vilma Santana, pesquisadora da Universidade Federal da Bahia (UFBA), considera que o campo da ST se diferencia por incorporar o conhecimento dos trabalhadores, o senso comum e os saberes populares, bem como o conhecimento que cabe à inovação, à tecnologia e à ciência. Mas questiona em que medida o conhecimento está dando conta dos segmentos de trabalhadores excluídos a partir de uma formulação teórica própria.

Da mesma forma Herval Pina Ribeiro, fundador do Diesat, coloca sua preferência pela pesquisa participante ou pesquisa-ação, pois seria a mais adequada ao campo, por ser aquela em que a voz do trabalhador é ouvida e considerada. Segundo ele, este tipo de pesquisa não atrai o financiamento público, mas é muitas vezes financiada por entidades de trabalhadores, como sindicatos e federações, ou até mesmo por recursos próprios de determinada classe.

Na pesquisa-ação, o sujeito da pesquisa não tem essa diferenciação entre pesquisador e o sujeito e como são ações, elas são no sentido de propiciar que os trabalhadores através dos seus sindicatos, simulem a dar a solução dos problemas. (H.P.R)

Como consequência da produção de conhecimento, a intervenção em saúde do trabalhador também se expressa na perspectiva normativa enquanto elaboração de políticas, proposição de novas leis e atualização de normas. Muitos desses processos se dão de forma participativa e são amplamente discutidos com os diversos grupos de interesses.

A primeira proposta de uma política de saúde do trabalhador foi de autoria do grupo de trabalho do Cesteh liderado por Anamaria Tambellini. Foi apresentada e aperfeiçoada a partir de grandes debates na I Conferência Nacional de Saúde do Trabalhador em $1986^{6}$. Esta proposta, aperfeiçoada na conferência, foi pautada na assembleia nacional constituinte com a pressão do movimento sindical e resultou na inserção da saúde do trabalhador na Constituição de $1988^{25}$ e na Lei Orgânica da Saúde ${ }^{26}$, o que se reproduziu nos estados e municípios em suas respectivas leis orgânicas.

Antes disso, porém, segundo Lia Giraldo, o sistema de vigilância epidemiológica do estado de São Paulo incluiu pela primeira vez, mediante a resolução do secretário de saúde em outubro de 1984, cinco agravos de notificação compulsória: as alterações hematológicas por exposição a hidrocarbonetos aromáticos, a disacusia neurosensorial, as dermatoses ocupacionais, as pneumoconioses e as fluoroses.

Em outros estados, como no Rio de Janeiro nos anos 1990, foram aprovadas legislações proibindo o jateamento de areia na indústria naval e o uso e comercialização de produtos derivados de amianto. Outros estados seguiram o mesmo caminho ${ }^{22}$.

Como área técnica do SUS, diversos trabalhos foram produzidos na perspectiva de sua estruturação, como destacado por Letícia Nobre sobre a revisão da Classificação Brasileira de Ocupações (CBO) e da Classificação Nacional de Atividades Econômicas (CNAE) para inclusão nos sistemas de informação da saúde (Sistema de Informação de Mortalidade - SIM e Sistema de Informação de Agravos de Notificação Sinan), por iniciativa da Organização Pan-Americana da Saúde (Opas).

Outro exemplo foi a caracterização de ofidismo como acidente de trabalho nos anos 1980, em pesquisa realizada por Luiz Galvão, que atuava na área de toxicologia, com o Instituto Butantã. Esta pesquisa foi utilizada pela Fundacentro para incluir o agravo na legislação vigente.

\section{A propagação da intervenção: formação e informação}

A formação em ST teve origem a partir da própria formação técnica e política de seus atores (profissionais de saúde e sindicalistas), na efervescência do Movimento da Reforma Sanitária Brasileira nos anos 1970, quando o país alcançou o primeiro lugar em 
mortes no trabalho. Havia então o entendimento de que a saúde da população passava necessariamente pela formação de profissionais que compreendessem a necessidade de mudanças na política de saúde, o que, por sua vez, passava por investimentos em saneamento básico, moradia, trabalho digno e seguro etc.

Lacaz relata que durante o período da ditadura militar, principalmente na segunda metade dos anos 1970, os partidos clandestinos de esquerda foram os principais agentes formadores políticos de profissionais de saúde, pois tinham inserção nas principais universidades do país. Em 1978, alguns médicos e outros profissionais articularam-se com o movimento sindical no sentido de assessorá-lo nas questões de saúde e trabalho. No mesmo ano foi criada a Comissão Intersindical de Saúde e Trabalho, que foi o embrião do Diesat.

[...] a minha trajetória tem uma militância nessa área por conta da própria estratégia do partido $\mathrm{Co}^{-}$ munista, e depois tem um envolvimento a partir do Diesat, que é esse órgão de assessoria sindical, e também dentro da Secretaria de Saúde, como coordenador dessa área de investigação. (F.A.C.L.)

Observamos também o crescimento da formação em ST no Brasil a partir da análise da produção bibliográfica dos programas de pós-graduação da área de Saúde Coletiva, que reuniu 667 artigos publicados em periódicos científicos entre 1998 e $2012^{22}$.

Para Carlos Minayo-Gomez, há necessidade de implementação de uma pedagogia da informação que avance na perspectiva de formação-ação, uma vez que os serviços deveriam se apropriar mais da produção acadêmica:

Eu acho que tem pessoas que vêm do serviço e que produzem com o intuito de contribuir para o serviço. Mas vou inverter: tem muitos estudos que os serviços deveriam se apropriar. [...] Contribuir para que isso avance com uma perspectiva de formação-ação. (C.M.G.)

Lia Giraldo aponta para a necessidade de uma grande capacitação nacional em ST, a partir da publicação da PNSTT em 2012, da mesma forma que houve em outros momentos para a vigilância epidemiológica. Esta capacitação se daria a partir de treinamentos básicos para todo o país. Na falta de um programa de formação em âmbito nacional, diversas iniciativas isoladas têm sido implementadas como cursos de atualização, aperfeiçoamento e especialização e à distância (EAD) e presenciais, além de mestrados profissionais (MP) em ST para a formação de técnicos que venham a se apossar de ferramentas metodológicas para seu cotidiano de trabalho, o que se traduz numa maior aproximação entre a academia e o serviço.
Recentemente, em 2017, foi instituído um grupo de trabalho de âmbito nacional para a elaboração de uma política de formação em saúde do trabalhador que contemple as diversidades e especificidades loco-regionais, numa perspectiva de insidir sobre as práticas profissionais, tendo como princípios integralidade, interdisciplinaridade e transversalidade na formação.

A incorporação das tecnologias de informação e comunicação propiciaram outras possibilidades para a construção de redes e intercâmbio de experiências e informações técnico-científicas para a intervenção em ST. Destacamos aqui algumas delas.

a) Fórum de Acidentes de Trabalho (http://www. forumat.net.br/), da Faculdade de Medicina da Universidade Estadual Paulista (Unesp) e da Faculdade de Saúde Pública da Universidade de São Paulo (USP): foi criado como um espaço de discussão e troca de experiências relativas à análise de acidentes de trabalho ${ }^{27}$.

b) Renast Online (http://renastonline.ensp.fiocruz.br): criada em 2009 como um repositório de experiências dos serviços e produção técnica e acadêmica da área. Tem por objetivo constituir uma plataforma de ferramentas e práticas de comunicação, formação permanente e utilização de informações para apoiar o fortalecimento da Rede Nacional de Atenção Integral à Saúde do Trabalhador ${ }^{28}$.

c) Pisat (http://ccvisat.wixsite.com/pisat): criado em 1995, o site do Programa Integrado em Saúde Ambiental e do Trabalhador (Pisat) da UFBA disponibiliza as bases do SIM, Sinan e SIH-SUS, além de boletins epidemiológicos de agravos à saúde do trabalhador, entre outras informações relevantes ${ }^{29}$.

d) Webcesteh: (http://www.cesteh.ensp.fiocruz.br/): a página do Cesteh tem por objetivo o incentivo à divulgação da produção e comunicação científica no campo da ST, o que inclui a socialização de resultados de pesquisas; a divulgação de ações de assistência e práticas de ensino na área; e a criação de banco bibliográfico temático e intercâmbio entre pesquisadores ${ }^{30}$.

e) SIG Saúde do Trabalhador (http://rute.rnp.br/ web/sig-saude-do-trabalhador): criado inicialmente para auxiliar no diagnóstico de agravos a ST à distância, recentemente tem sido também utilizado como ferramenta para capacitação dos profissionais da Renast por meio de encontros e oficinas on-line ${ }^{31}$.

f) Observatório de SST (https://observatoriosst. mpt.mp.br/): ferramenta de gestão do conhecimento e de promoção do trabalho decente, tem grande potencial para informar políticas 
públicas de prevenção de acidentes e doenças no trabalho - de modo que estas passem cada vez mais a ser orientadas por dados e evidências - e para promover o desencadeamento, o monitoramento e a avaliação de iniciativas de prevenção ${ }^{32}$.

g) Blog Multiplicadores de Visat (https://www. multiplicadoresdevisat.com): é um canal de comunicação e divulgação das atividades relacionadas à formação de agentes de Visat, no âmbito da Renast, tendo como foco a implementação das ações de vigilância definidas como prioritárias nos diversos níveis da rede do SUS (nacional, macrorregional, estadual, municipal) ${ }^{33}$.

Diversas páginas criadas pelos Cerest possuem bastante material produzido nos estados e municípios (principalmente as capitais). Destaca-se o site do Cerest-BA pela vasta produção técnica e informações em saúde do trabalhador ${ }^{34}$.

Esses são alguns exemplos relevantes de ferramentas disponíveis na internet para subsidiar as ações de Visat, bem como contribuição para a formação e comunicação na área.

\section{Considerações finais}

Foram aqui destacadas as origens da intervenção do setor saúde sobre o adoecimento relacionado ao trabalho a partir de uma vertente originada no movimento político-sindical nos anos 1970 e 1980 e assumida por meio da mobilização de profissionais de saúde engajados na luta da população por melhores condições de vida e trabalho. Essa foi a base para a estruturação de serviços, a incorporação da saúde do trabalhador enquanto ação do Estado para a pesquisa na área.

A intervenção em saúde do trabalhador tem como expressão máxima a Visat, que, ao agregar as relações de trabalho ao objeto da saúde, resgata para o setor a possibilidade, a capacidade e a responsabilidade de intervir nos processos determinantes dos agravos advindos desse binômio, especialmente nos processos e ambientes de trabalho. No entanto, a implementação de medidas para soluções dos problemas relativos ao processo saúde-doença e trabalho dependem mais de questões de poder e capacidade reivindicativa do que questões técnico-operativas ${ }^{35}$.

A institucionalização da saúde do trabalhador pela estratégia da Renast evidenciou a necessidade de se estabelecer formas mais eficazes de comunicação e de troca de saberes. Adicionalmente, remeteu a uma premência de formação de profissionais de saúde tanto para suprir as necessidades da área como para capacitar os demais profissionais do SUS. Para tanto, novas estratégias educacionais têm sido formalizadas, como cursos à distância e mestrados profissionais.

A intervenção em saúde do trabalhador também se expressa nas modalidades de pesquisa-ação, pesquisa-intervenção e comunidade ampliada de pesquisa, que afirmam o protagonismo dos trabalhadores e a valorização da subjetividade para os processos de transformação.

\section{Contribuições de autoria}

Strausz MC contribuiu com a concepção do projeto de pesquisa, a realização das entrevistas, a análise das informações, a elaboração do manuscrito e sua aprovação final. Guilam MCR e Oliveira SS contribuíram com a análise das informações, a elaboração e revisão crítica do manuscrito e sua aprovação final. Todas as autoras assumem integral responsabilidade pelo trabalho e conteúdo publicado.

\section{Referências}

1. Minayo-Gomez C, Thedim-Costa SMF. Incorporação das ciências sociais na produção de conhecimentos sobre trabalho e saúde. Ciênc Saúde Coletiva. 2003;8(1):125-36.

2. Laurell AC. Saúde e trabalho: os enfoques teóricos. In: Nunes ED, organizador. As Ciências Sociais em Saúde na América Latina: tendências e perspectivas. Brasília: Organização Pan-Americana de Saúde; 1985. p. 255-76.
3. Mendes R, Dias EC. Da medicina do trabalho à saúde do trabalhador. Rev Saúde Públ [Internet]. 1991 [citado em 15 jan. 2012];25(5):341-9. Disponível em: https://scielosp.org/pdf/rsp/1991. v25n5/341-349/pt

4. Lacaz FAC. Saude do trabalhador: um estudo sobre as formações discursivas da academia dos serviços e do movimento sindical [tese] [Internet]. Campinas: Unicamp; 1996 [citado em 15 jan. 
2012]. Disponível em: http://www.bibliotecadigital. unicamp.br/document/?code $=000114922$

5. Lacaz FAC. Conhecimentos, práticas em TrabalhoSaúde e as abordagens da medicina social e da medicina do trabalho no Brasil: final do século XIX até os anos 1950-60. Cad Psicol Soc Trab [Internet]. 2007 [citado em 15 jan. 2012];10(1). Disponível em: http://www.revistas.usp.br/cpst/article/ view/25811

6. Tambellini AT, Porto MFS, Galvão L, Machado JMH. Política Nacional de Saúde do Trabalhador: análises e perspectivas. Rio de Janeiro: Escola Nacional de Saúde Pública; 1986.

7. Laurell AC, Noriega M. Processo de produção e saúde: trabalho e desgaste operário. São Paulo: Hucitec; 1989.

8. Lacaz FAC. Saúde dos trabalhadores: cenário e desafios. Cad Saúde Pública [Internet]. 1997 [citado em 31 jul. 2014];13(supl 2):7-19. Disponível em: http://www.scielo.br/scielo.php?script=sci arttext\&pid $=$ S0102-311X1997000600002\&lng $=$ pt\& $\mathrm{nrm}=$ iso\&tlng $=\mathrm{pt}$

9. Lacaz FAC. O campo Saúde do Trabalhador: resgatando conhecimentos e práticas sobre as relações trabalho-saúde. Cad Saúde Pública. 2007;23(4):757-66.

10. Oddone I. Ambiente de trabalho: a luta dos trabalhadores pela saúde. São Paulo: Hucitec; 1986.

11. Berlinguer G. A saúde nas fábricas. São Paulo: Hucitec; 1978.

12. Possas CA. Saúde e trabalho: a crise da Previdência Social. São Paulo: Hucitec; 1989.

13. Machado JMH. Processo de vigilância em saúde do trabalhador. Cad Saúde Pública [Internet]. 1997 [citado em 3 maio 2014];13(supl 2):3345. Disponível em: http://www.scielo.br/scielo. php?script $=$ sci_arttext\&pid $=$ S0102-311X19970006 $00004 \& \operatorname{lng}=\mathrm{pt} \& \mathrm{nrm}=\mathrm{iso} \& \operatorname{tng}=\mathrm{pt}$

14. Muniz HP, Brito J, Souza KR, Athene M, Lacomblez M. Ivar Oddone and his contribution to Worker's Health in Brazil. Rev Bras Saúde Ocupacional. 2013;38(128):280-91.

15. Brito JC. A Ergologia como perspectiva de análise: a saúde do trabalhador e o trabalho em saúde. In: Minayo C, Machado JMH, Pena GL. Saúde do trabalhador na sociedade brasileira contemporânea. Rio de Janeiro: Editora Fiocuz; 2011. p. 480-94.

16. Souza KR, Mendonça ALO. Saúde do trabalhador e educação: reflexões a partir do modelo operário de conhecimento. Trab Necessário. 2013;11(14):1-32.

17. Vasconcelos LCF. Saúde, trabalho e desenvolvimento sustentável: apontamentos para uma política de Estado [tese]. Rio de Janeiro: Fiocruz; 2007.

18. Minayo-Gomez C. Historicidad del concepto "salud del trabajador" en el ámbito de la salud colectiva: el caso de Brasil. Salud Colect [Internet]. 2012 [citado em 4 fev. 2013];8(3):221-7. Disponível em: http://www.scielo.org.ar/scielo.php?script =sci arttext\&pid $=$ S1851-82652012000400001\&lng $=$ es\& $\mathrm{nrm}=\mathrm{iso}$

19. Brasil. Ministério de Estado da Saúde. Portaria $\mathrm{n}^{\circ} 3.120$, de $1^{\circ}$ de julho de 1998. Renast Online [Internet]. 1 jul. 1998 [citado em 22 maio 2019]. Disponível em: http://renastonline.ensp.fiocruz.br/ recursos/portaria-3120-1o-julho-1998

20. Strausz MC. Produção do conhecimento em saúde coletiva: um olhar a partir da saúde do trabalhador [tese]. Rio de Janeiro: Fundação Oswaldo Cruz; 2014.

21. Minayo M. O desafio do conhecimento: pesquisa qualitativa em saúde. 12. ed. São Paulo; Rio de Janeiro: Hucitec; Abrasco; 2010.

22. Nobre LCC. A política de saúde do trabalhador no Brasil e na Bahia. In: Nobre L, Pena GLP, Baptista $\mathrm{R}$, organizadores. A saúde do trabalhador na Bahia: história, conquistas e desafios. Salvador: Edufba; Sesab; Cesat; 2011. p. 23-92.

23. D’Acri V, Marques MB, Reis SK. A indústria têxtil do amianto e de cimento-amianto e a luta pela saúde no Rio de Janeiro. In: Bravo MI, D’Acri V, Bilates JM, organizadoras. Movimentos sociais, trabalho e saúde. Rio de Janeiro: Fundação Oswaldo Cruz; 2010. p. 135-58.

24. Gómez CM. Avanços e entraves na implementação da Política Nacional de Saúde do Trabalhador. Rev Bras Saúde Ocup. 2013;38(127):11-30.

25. Brasil. Presidência da República. Constituição da República Federativa do Brasil de 1988. Diário Oficial da União [Internet]. 5 out. 1988 [citado em 27 maio 2019];191-A:1. Disponível em: http://www.planalto. gov.br/ccivil_03/constituicao/constituicao.htm

26. Brasil. Presidência da República. Lei no 8.080, de 19 de setembro de 1990. Diário Oficial da União [Internet]. 20 set. 1990 [citado em 27 maio 2019]:18055. Disponível em: http://www.planalto. gov.br/ccivil_03/leis/l8080.htm

27. Fórum de Acidentes de Trabalho [Internet]. 2008 [acesso em 11 mar. 2018]. Disponível em: http:// www.forumat.net.br/at

28. Rede Nacional de Atenção Integral à Saúde do Trabalhador. Renast Online [Internet]. 2009 [citado em 11 mar. 2018]. Disponível em: http:// renastonline.ensp.fiocruz.br/tags/renast

29. Programa Integrado em Saúde Ambiental e do Trabalhador (PISAT). Centro Colaborador da Vigilância aos Agravos à Saúde do Trabalhador [Internet]. 2016 [citado em 11 mar. 2018]. Disponível em: http://ccvisat.wixsite.com/pisat

30. Centro de estudos de Saúde do Trabalhador e Ecologia Humana. Cesteh [Internet]. 2017 [atualizado em 13 maio 2019; citado em 11 mar. 2018]. Disponível em: http://www.cesteh.ensp. fiocruz.br/

31. SIG Saúde do Trabalhador. Rede Universitária de Telemedicina [Internet]. 29 nov. 2011 [citado em 
11 mar. 2018]. Disponível em: http://rute.rnp.br/ web/sig-saude-do-trabalhador

32. Observatório de Saúde e Segurança no Trabalho [Internet]. Brasília, DF: Ministério Público do Trabalho; 2017 [citado em 11 mar. 2018]. Disponível em: https://observatoriosst.mpt.mp.br/

33. Multiplicadores de VISAT [Internet]. 2017 [citado em 11 mar. 2018]. Disponível em: https://www. multiplicadoresdevisat.com
34. Diretoria de Vigilância e Atenção à Saúde do Trabalhador [Internet]. Salvador: Governo do Estado da Bahia; 2018 [citado em 28 maio. 2019]. Disponível em: http://www.saude.ba.gov.br/suvisa/ divast/

35. Almeida GE. Pra que somar se a gente pode dividir? Abordagens integradoras em saúde, trabalho e ambiente [dissertação]. Rio de Janeiro: Escola Nacional de Saúde Pública; 2000. 
No manuscrito "A intervenção em saúde do trabalhador na perspectiva dos atores históricos do campo", DOI: http://dx.doi.org/10.1590/2317-6369000015118, publicado no periódico Revista Brasileira de Saúde Ocupacional, 44:e25, na página 4/10,

\section{Onde se lia:}

"Francisco Lacaz relata que foi diretor de uma unidade de saúde nos anos 1970, depois coordenou o Instituto de Saúde, que não era uma estrutura formal, mas que teve um papel importante, de nucleação de pesquisas. Esta instância do governo de São Paulo se propunha a ser o órgão de pesquisa da secretaria de saúde. Desta forma, ao mesmo tempo em que desenvolvia práticas na rede, como na criação de PST, também era um espaço de investigação. Em São Paulo houve a expansão do modelo de PST para outras regionais de saúde do estado, como o PST Rural, com a questão dos agrotóxicos no Vale da Ribeira, e uma vertente de investigação sobre o mercúrio e ainda das lesões por esforço repetitivo, por conta da demanda dos bancários no ABC Paulista."

\section{Leia-se:}

"Francisco Lacaz relata que nos anos 1980 coordenou, no Instituto de Saúde da Secretaria de Estado da Saúde de São Paulo, a área técnica 'Trabalho e Saúde', que teve papel importante de nucleação de pesquisas e expansão do modelo de Programas de Saúde do Trabalhador (PST) para outras regionais de saúde do estado, como as investigações sobre exposição ao mercúrio e sobre as lesões por esforço repetitivo, esta por conta da demanda dos bancários no ABC Paulista, e ainda o PST Rural, que lidava com a questão dos agrotóxicos no Vale da Ribeira." 


\section{Errata}

No manuscrito "A intervenção em saúde do trabalhador na perspectiva dos atores históricos do campo", DOI: http://dx.doi.org/10.1590/2317-6369000015118, publicado no periódico Revista Brasileira de Saúde Ocupacional, 44:e25, na página 1/10,

\section{Onde se lia:}

"Simone Santos Oliveira ${ }^{\mathrm{a}}$

(D) https://orcid.org/0000-0002-6071-2945”

\section{Leia-se:}

"Simone Santos Oliveira ${ }^{\mathrm{a}}$

(D) https://orcid.org/0000-0001-5477-6216” 